\title{
KLERIKUS DILARANG BERPOLITIK PRAKTIS Promosi Agar Klerikus Aktif Berpolitik Kepedulian Sosial
}

\author{
Largus Nadeak* \\ Program Studi Ilmu Filsafat, Fakultas Filsafat, Unika Santo Thomas \\ Email: Gonzales.nadeak@kapusin.org
}

\begin{abstract}
Abstrak
Setiap umat Kaktolik otomatis anggota masyarakat satu negara. Setiap umat Katolik baik para klerikus dan awam dipanggil untuk terlibat aktif berpolitik. Kegiatan politik merupakan seni mengatur dan mengurus negara yang mencakup penetapan bentuk, semua kebijakan/tindakan demi kesejahteraan masyarakat, dan mempertanggungjawabkannya. Umat awam diharapkan terlibat dalam politik praktis dan politik kepedulian sosial. Para klerikus dilarang berpolitik praktis tetapi harus telibat aktif dalam politik kepedulian sosial. Larangan ini jelas disebut dalam KHK 1983, kan. 287, 2, para klerikus "Jangan turut ambil bagian aktif dalam partai-partai politik dan dalam kepemimpinan serikat-serikat buruh, kecuali jika menurut penilaian otoritas gerejawi yang berwenang hal itu untuk melindungi hak-hak Gereja atau memajukan kesejahteraan umum." Anggota klerikus yang berusaha terlibat dalam politik praktis tanpa disetujuai oleh pimpinannya, bukan hanya melawan KHK tetapi melawan kesadaran pilihan sebagai anggota klerikus. Umat awam hendaknya mendukung para klerikus untuk tetap bangga dalam panggilan sebagai anggota klerikus dalam menggunakan pengaruhnya politis kepedulian sosialnya dalam memperjuangkan hak-hak Gereja dan kesejahteraan umum masyarakat secara keseluruhan.
\end{abstract}

Kata-kata kunci: klerikus, politik praktis, kepedulian sosial, Gereja, Hukum Gereja, kesejahteraan umum.

\section{Pendahuluan}

Pernah terjadi, seorang imam mencalonkan diri dan kampanye agar menjadi anggota DPRD, dan imam lain menjadi calon bupati. Beberapa umat Katolik mendukung, bahkan ikut menjadi tim sukses, tetapi beberapa umat keberatan. Muncul pertanyaan lama, bolehkah

\footnotetext{
* Largus Nadeak, lisensiat dalam bidang Teologi Moral; lulusan Universitas Lateranensis Academia Alfonsiana, Roma; dosen Teologi Moral pada Fakultas Filsafat Unika St. Thomas, Sumatera Utara.
} 
seorang klerikus berpolitik praktis? Dalam Kitab hukum Kanonik jelas digariskan bahwa klerikus dilarang berpolitik praktis.

Yang jelas sebagai anggota masyarakat seorang klerikus dipanggil untuk terlibat berpolitik, tetapi bukan berpolitik praktis, tetapi berpolitik ketelibatan sosial. Ajaran sosial Gereja menganjurkan agar semua umat (klerikus dan awam) terlibat dalam politik sesuai dengan tujuan sejatinya yaitu memperkuangkan kesejahteraan umum (bonum commune). Gereja Katolik bukan lembaga politik, tetapi umatnya (awam) seharusnya berperan aktif di areal politik praktis.

\section{Pengertian Berpolitik}

Kata politik berasal bahasa Yunani: polis yang berarti negara kota, dan rakyat yang hidup di dalam negara kota tersebut. Dalam polis semua warga terlibat untuk menata kota sedemikian rupa sehingga warga kota hidup sejahtera dan damai. Di dalamnya semua warga negara sederajat. ${ }^{1}$ Polis memiliki ciri: otonomi, swasembada dan merdeka. Pusat polis adalah agora yang menjadi pasar, tempat pertemuan dan diskusi. ${ }^{2}$ Kegiatan politik merupakan seni mengatur dan mengurus negara atau ilmu kenegaraan yang mencakup penetapan bentuk, semua kebijakan/tindakan, dan mempertanggungjawabkannya.

Dewasa ini politik merupakan struktur dan upaya mengatur hidup bersama dalam masyarakat. Berpolitik memiliki 2 muatan: 1) Sturktur, kuasa, pemerintahan, yang secara pribadi dan bersama memiliki maksud tertentu; 2) Aktivitas yang menentukan nilai dan kriteria untuk hidup bersama. Tujuan kegiatan politik yang ditopang oleh trias politik (legislatif, eksekutif, dan judikatif adalah mengusahakan kesejahteraan umum (bonum commune). Politisi sejati adalah orang yang dipercayai rakyat untuk mengurus kepentingan bersama dan kesejahteraan bersama (umum), yang mencakup: ekonomi, sosial, pendidikan, dll. ${ }^{3}$

\footnotetext{
${ }^{1}$ Para pendatang, budak, kaum wanita tidak ambil bagian dalam urusan negara.

${ }^{2}$ K. Bertens, Sejarah Filsafat Yunani, (Yogyakarta, Kanisius, 1987), hlm. 19-22; Adolf Heuken, Ensiklopedia Gereja 7, (Jakarta, Yayasan Cipta Loka Caraka, 2005), hlm. 25.

${ }^{3}$ E. Chiavacci, "Politica", dalam Francesco Compagnoni, cs, Nuovo Dizionario di Teologia Morale, (Torino, San Paolo, 1990), hlm 953. Hesri Cengga, "Etimologi dan Fenomena Politik Indonesia sampai Saat ini”, dalam Kompasiana, diperbarui 27 Maret 2017
} 


\section{Panggilan Berpolitik}

Semua manusia lahir dalam konteks bernegara dan bermasyarakat. Bumi dan isinya sudah dibagi dalam banyak negara, sehingga semua orang hidup di atasnya berkonteks berpolitik. Setiap umat Katolik baik klerikus maupun awam adalah bagian warga masyarakat satu negara, maka otomatis bagian dari masyarakat politis dan dipanggil untuk terlibat berpolitik. Dokumen Lumen Gentium ${ }^{4}$ dan Gaudium et Spes $^{5}$ memuat keterlibatan Gereja di dalam masyarakat tanpa melupakan dirinya sebagai komunitas yang menjadi tanda dan sarana keselamatan bagi dunia. ${ }^{6}$

Gereja partikular yang dipimpin Uskupnya secara jelas tidak berpolitik praktis. Umat Gereja awam yang memang masyarakat satu negara harus terjun aktif dalam berpolitik praktis dengan terang hati nurani. Dengan berpolitik praktis kaum awam menyuarakan visi moral politis hidup bermasyarakat yaitu membela martabat manusia dan merealisasikan kesejahteraan umum (bonum commune) berdasarkan iman Katolik yang benar. .

Keterlibatan politik dapat dibagi dua (2): Keterlibatan politik kepedulian sosial dan politik praktis.

\section{Berpolitik Kepedulian Sosial}

Berpolitik kepedulian sosial merupakan panggilan orang beriman baik klerikus maupun awam. Panggilan ini merupakan penerapan Ajaran

\footnotetext{
${ }^{4}$ Konsili Vatikan II, "Lumen Gentium" dalam Dokumen Konsili Vatikan II, diterjemahkan oleh R. Hardawiryana (Jakarta: Komunetasi dan Penerangan KWI - Obor, 1993), no. 3136.

${ }^{5}$ Konsili Vatikan II, "Gaudium et Spes" dalam Dokumen Konsili Vatikan II, diterjemahkan oleh R. Hardawiryana (Jakarta: Komunetasi dan Penerangan KWI - Obor, 1993), no. 7376.

${ }^{6}$ Marciano Vidal, Manuale di Etica Teologica 3, Morale Sociale, (Assisi, Cittadella, 1997), hlm. 698; bdk. Mateus Mali, Konsep Berpolitik Orang Kristiani. (Yogyakarta, Kanisius), 2014, hlm. 146.

${ }^{7}$ Ratzinger, Joseph. Catatan Ajaran pada Beberapa Pertanyaan Berbubung dengan Peranserta Umat Katolik di dalam Kehidupan Politik, (Jakarta, Dokpen KWI, 2003), no. 6; bdk. Marciano Vidal, Manuale di Etica Teologica 3..., hlm. 687-88; Mateus Mali, Konsep Berpolitik..., hlm. 155-156.
} 
Sosial Gereja agar efektivitas sakramen (khususnya sakramen Krisma dan Ekaristi) berdaya dan dialami dalam kesatuan perayaan ritual dan tindakan real sebagai umat gereja dan warga masyarakat dalam satu negera. Visi moral politis yaitu menghormati martabat manusia dan kesehateraan umum, diperjuangkan dalam misi yang terealisir dalam perbuatan real.

\section{Berpolitik Praktis}

Politik praktis adalah struktur dan upaya untuk memperoleh kekuasaan politik, baik bagi diri sendiri sebagai perseorangan atau atas nama partai. Dalam hal ini seseorang terlibat mencari kedudukan dan melaksanakannya dalam satu lembaga negara, sebagai perseorangan atau pun atas nama kelompok/partai. Disebut juga kegiatan politik praktis kalau seseorang membantu orang lain atau partai tertentu untuk memperoleh kekuasaan sesuai dengan aturan main yang berlaku dalam sistem politik yang ada. Berpolitik praktis merupakan panggilan awam untuk terlibat dalam struktur dan kegiatan politis, dengan berpartisipasi akrif di trias politika dan bidang politis lain.

Faktual bahwa sistem dan kegiatan politik praktis sering disindir memerankan "permainan kotor", sehingga sering kita dengar bahwa "politik kotor". Sebutan demikian muncul karena cara dan tindakan berpolitik yang diperkan sering tidak mengindahkan etika politik yang baik dan benar. Politik praktis biasanya secara taktis berusaha memperjuangkan kekuasaan. ${ }^{8}$

\section{Klerikus Dilarang Berpolitik Praktis}

Dalam KHK dirumuskan: "Oleh penetapan ilahi, di antara kaum beriman kristiani dalam Gereja ada pelayan-pelayan suci, yang dalam hukum juga disebut para klerikus; sedangkan lain-lainya disebut awam."9 Klerikus adalah "Golongan orang beriman yang menerima tahbisan

\footnotetext{
${ }^{8}$ Yong Ohoitimur, "Pelaksanaan Otonomi Daerah: Berpeganglah pada Etika Politik", dalam Anicetus B. Sinaga et al, Etos dan Moralitas Politik, Seni Pengabdian untuke Kesejabteraan Umum, (Yogyakarta, Kanisius, 2004), hlm. 223-224.

9 Kitab Hukum Kanonik (Codex Iuris Canonici, 1983), diterjemahkan oleh Sekretariat KWI, ((Jakarta: Obor, 1999), Kan. 207, 1.
} 
diakon, imam atau uskup."10 Mereka memiliki tugas suci bukan diberikan oleh umat beriman atau lembaga tertentu, tetapi diberikan oleh Kristus, untuk melayani dan membimbing umat agar menghidupi Injil dan merayakan sakramen-sakramen. ${ }^{11}$

Ada beberapa hal diawaskan untuk para klerikus, antara lain:

- Para klerikus hendaknya menghindari hal-hal yang asing bagi status klerikus, walau secara umum dilihat bahwa hal tersebut tidak tercela. ${ }^{12}$

- "Para klerikus janganlah mendirikan atau mengambil bagian dalam perkumpulan-perkumpulan yang tujuannya atau kegiatannya tidak dapat diselaraskan dengan kewajiban-kewajiban yang khas bagi status klerikal, atau dapat menghambat pelaksanaan seksama tugas yang dipercayaka otoratas Gereja yang berwenang kepada mereka."13

- Para klerikus dilarang menerima jabatan-jabatan publik yang membawa serta partisipasi dalam pelaksanaan kuasa sipil. ${ }^{14}$

Klerikus dan anggota lembaga hidup bakti dilarang berpolitik praktis yang cenderung tergelincir ke kepentingan kelompok dan temporal (sesaat). Klerikus hendaknya tidak diseret dan diperalat orang tertentu atau partai tertentu ke areal politik praktis.

Dasar yuridis klerikus dilarang berpolitik praktis adalah Kitab Hukum Kanonik (KHK) 1983. Para klerikus "Jangan turut ambil bagian aktif dalam partai-partai politik dan dalam kepemimpinan serikat-serikat buruh, kecuali jika menurut penilaian otoritas gerejawi yang berwenang hal itu untuk melindungi hak-hak Gereja atau memajukan kesejahteraan umum."15 Larangan berpolitik praktis juga dikenakan pada anggota Lembaga Hidup Bakti yang bukan klerikus. ${ }^{16}$

Berpolitik praktis yang dilarang untuk klerikus dan anggota Lembaha Hidup Bakti berhubungan dengan ide berpolitik praktis di atas.

10 Adolf Heuken, Ensiklopedia Gereja 4, (Jakarta, Yayasan Cipta Loka Caraka, 2005), hlm. 234.

${ }^{11}$ Adolf Heuken, Ensiklopedia Gereja 4..., hlm. 234.

${ }^{12}$ Kan. 285, 2

${ }^{13}$ Kan. 278, 3.

${ }^{14}$ Kan. 285, 3.

${ }^{15}$ Kan. 287, 2

16 Kan. 672. 
Secara jelas larangan tersebut berisi pesan agar klerikus tidak terlibat dalam politik kekuasaan (kekuasaan politis). Klerikus dilarang menduduki jabatan poltik kekuasaan. Di samping itu dilarang juga secara aktif dan eksplisit mendukung dan bekerja untuk suatu ideologi politik tertentu. ${ }^{17}$

Alasan larangantersebut sesuai tujuan tahbisan dan belajar dari sejarah. Tujuan utama klerikus secara resmi ditahbiskan dan tujuan pelayanan tahbisan adalah untuk menyatakan keselamatan Kristus melalui kata-kata dan perbuatan. Tugas utama seorang klerikus berhubungan dengan hal rohani dan keselamatan jiwa. Klerikus bukan pemimpin sosial atau pemimpin politik atau penguasa hal-hal temporal. Klerikus jangan berpura-pura melayani Injil dengan ketelibatan hebat pada hal-hal yang sementara. Klerikus hendaknya menjadi tanda dan faktor permersatu persaudaraan dan memperjuangkan kesejahteraan umu. Kalau klerikus terlibat dalam hal politis kekuasaan yang temporal akan dengan mudah dirinya menjadi sumber perpecahan.

Dalam sejarah, keterlibatan para klerikus dalam politik praktis justru membuat misi Gereja menyimpang dari rel kehendak ilahi. Keterlibatan klerikus dalam politik praktis tidak sesuai dengan tahbisan sucinya. Pada masa Fransiskus Assisi para klerikus terlibat dalam bidang politik praktis. Sejarah Gereja di Prancis bisa menjadi pelajaran berharga agar para klerikus tidak mengulangi keterlibatan politik praktis. ${ }^{18}$ Dalam sejarah terjadi bahwa wajah demonik agama lebih jelas dari wajah angeliknya. Agama pun sangat mudah dijadikan sebagai alat politik. Pada tataran ini agama pasti dilanda demoralisasi. ${ }^{19}$ Tentu klerikus dan umat harus berperan dalam kondisi masyarakat yang tidak sempurna, tetapi

\footnotetext{
${ }^{17}$ Konsili Vatikan II, "Persbyterorum Ordinis" dalam Dokumen Konsili Vatikan II, diterjemahkan oleh R. Hardawiryana (Jakarta: Komunetasi dan Penerangan KWI Obor, 1993), no. 6.

18 Eddy Kristiyanto, "Pelajaran dari Barat: Kajian atas Relasi Gereja dan Negara dari Perspektif Historis", dalam dalam Anicetus B. Sinaga et al Etos dan Moralitas Politik..., hlm. 92, 117-118.

${ }^{19}$ Fabianus Sebastian Heatubun, "Dari Etika ke Estetika: Paradigma Alternatif Mengatasi Krisis Nilai”, dalam Anicetus B. Sinaga et al, Etos dan Moralitas Politik..., hlm. 233.
} 
posisi dan kegiatan politik yang dijiwai oleh pesrpektif utopis yang menjauhkan orang dari Allah, kenabian palsu harus ditolak. ${ }^{20}$

Ada kondisi bahwa larangan berpolitik praktis untuk para klerikus tidak berlaku, yaitu demi melindungi hak-hak Gereja dan memajukan kesejahteraan umum. Syaratnya, klerikus harus mendapat persetujuan dari kuasa gerejawi yang berwenang (Uskup). Uskup yang menilai apakah hak Gereja dan kesejahteraan umum menuntut seorang klerikus untuk berpolitik praktis. Uskup memberi batas waktu, agar jelas bahwa klerikus terlibat bukan karena mencari uang dan kuasa, tetapi karena "terpaksa" oleh semangat Injil untuk melindungi hak Gereja dan bonum commune. ${ }^{21}$

Kalau klerikus ngotot berpolitik praktis maka Uskup menegur klerikus tersebut. Kalau teguran tidak diindahkan maka klerikus tersebut bisa kena suspensi (dia tetap seorang klerikus), dilarang untuk melaksanakan semua atau beberapa perbuatan kuasa tahbisan. Larangan ini bersifat sementara, sampai dia bertobat. Kalau klerikus tersebut tetap berkeras (tidak bertobat), hanya demi kuasa dan cenderung akan melakukan pelanggaran berat dalam perpolitikan maka Uskup bisa mengambil keijakan yang sesuai, bahkan ada saatnya lebih tegas sampai mengajukan pemecatan klerikus tersebut (hilang status fungsional klerikus).

\section{Klerikus Promotor Berpolitik Kepedulian Sosial}

Berpolitik yang sejati adalah mengambil posisi memperjuangkan kesejahteraan umum secara khusus berpihak pada orang miskin (preferential opsion for the poor). Para klerikus hendaknya memberi pengaruh politik, sebagaimana Yesus lakukan pada masanya, yaitu menentang kemunafikan dan memperjuangkan kejujuran dan keadilan, tanpa kekerasan. Klerikus melakoni panggilan berpolitik kepedulian sosial di panggung gereja (umat) untuk secara arif membela dan melindungi hak dan kewajiban Gereja dan juga membela kepentingan

\footnotetext{
${ }^{20}$ Ratzinger, Joseph. Catatan Ajaran pada Beberapa Pertanyaan..., no. 7.

${ }^{21}$ Anicetus B. Sinaga et al. "Penataan Ormas Katolik dalam Indonesia Baru", dalam Anicetus B. Sinaga et al Etos dan Moralitas Politik..., hlm. 60.
} 
masyarakat secara umum dalam membela keadilan, kebenaran, dan memperjuangkan damai. ${ }^{22}$

Klerikus memerankan politik kepedulian sosial dalam beberapa kesempatan dan tindakan, antara lain:

- Ikut memberi suara dalam memilih anggota legislatif dan anggota eksekutif.

- Membantu umat agar menggunakan hati nurani dalam menjatuhkan pilihan ketika ada pemilihan anggota legislatif (pileg) maupun pemilihan presiden dan kepala daerah. Mata hati umat dibantu untuk melihat kenyataan sehingga suara hati berdaya memilih orang yang paling sedikit pelanggaran yang dilakukan.

- Berbicara tentang politik kesejahteraan umum, "Para klerikus hendaknya selalu memupuk damai dan kerukunan dengan sekuat tenaga berdasarkan keadilan yang harus dipelihara di antara sesama manusia." 23

- Mengkritisi kebijakan politik terlebih kebobrokan kekuasaan. Lalu menyebarkan pesan inspiratif dan pengaruh politik yang positif dan signifikan.

- Menyerukan norma dan prinsip etis politis, serta terjun membela keadilan dan kesejahteraan bersama.

Para klerikus seharusnya menjadi promotor politik keterlibatan sosial. Inspirasi gerakan politik kepedulian sosial bersumber dari Kitab Suci, "Jangan kamu kalah terhadap kejahatan, tetapi kalahkan kejahatan dengan kebaikan" (Rm 12, 21). Para klerikus (sendiri atau dengan bantuan orang lain) seharusnya mendampingi dan menganimasi Komisi Kerasulan Awam dalam keterlibatannya dalam berpolitik keterlibatan sosial dan berpolitik praktis. Pendidikan dan pengkaderan tokoh politik awam menjadi tugas bersama. Gereja membutuhkan umat yang cerdas berdiplomasi demi kepentingan Gereja dan kesejahteraan umum. Jabatan publik dan istitusi sosial-politik merupakan instrumen untuk mengupayakan hidup baik untuk kebersamaan. Komisi Kerasulan Awam

\footnotetext{
22 Mateus Mali, Konsep Berpolitik Orang Kristiani..., hlm. 147-148.

${ }^{23}$ Kan. 287, 1
} 
hendaknya membahas politik sebagai keterlibatan Gereja dalam bernegara demi kesejahteraan umum. Dengan keterlibatan politik Gereja berperan sebagai saksi yang menggarami masyarakat. Gereja dengan perjuangannya larut perjuangan kesejahteraan masyarakat tetapi tidak hanyut dalam kejahatan. ${ }^{24}$

Gereja Katolik melengkapi ajaran sosialnya dengan suatu etika politik yang bertujuan agar masyarakat dan negara ditata sedemikian rupa hingga martabat setiap orang sebagai manusia dilindungi dan setiap warga didukung agar dapat hidup sejahtera sesuai dengan cita-citanya. Ada 8 prinsip etika politik Katolik Pasca Konsili Vatikan II: 1) Prinsip Kebaikan hati, 2) Prinsip Keberpihakan pada Kehidupan, 3) Prinsip Kesejahteraan Umum, 4) Prinsip Subsidiaritas, 5) Prinsip Solidaritas, 6) Hak-hak Azasi Manusia, 7) Prinsip Penolakan terhadap Kekerasan, 8) Persaudaraan Semesta. $^{25}$

Keterlibatan para klerikus berpolitik kepedulian sosial menjadikan sakramen khususnya sakramen Krisma dan sakramen Ekaristi berefek keselamatan. Efektivitas sakramen yang menyelamatkan terjadi dalam kesatuan perayaan ritual dan tindakan real di hidup bersama beragama dan bernegara. Dengan daya sakramen Krisma, umat awam dan klerikus menyatakan peran publik untuk berani membela kebaikan dan kebenaran dalam tuntunan Roh Kudus. Dengan daya sakramen Ekaristi orang beriman berdaya berkorban dan bersolidaritas dalam hidup bersama di masyarakat.

\section{Penutup}

Gereja sebagai institusi iman tidak berpolitik praktis tetapi ikut terlibat aktif dalam gerakan politik kepedulian sosial. Para klerikus yang ditahbiskan memiliki tugas suci bukan diberikan oleh lembaga sosial tertentu, tetapi diberikan oleh Kristus, untuk melayani dan membimbing umat agar menghidupi Injil dan merayakan sakramen-sakramen. Agar sakramen efektif, yaitu menghasilkan keselamatan dan kesejahteraan

\footnotetext{
${ }^{24}$ Yong Ohoitimur, "Pelaksanaan Otonomi Daerah...", hlm. 221, 225.

25 Franz Magnis-Suseno, Katolik itu Apa, Sosok, Ajaran, Kesaksiannya, (Yogyakarta, Kanisisus, 2017), hlm. 184-185.
} 
untuk umat yang merayakan dan untuk sesamanya, harus ada kesatua perayaan riutal dan tindakan real yang diwujudkan dalam hidup sosial. Banyak jalan pastoral yang bisa ditempuh oleh para klerikus untuk mewujudkan misi Kerajaan Allah (penyelamatan semua manusia dan ciptaan lain) di ranah politik kepedulian sosial tanpa terlibat aktif di zona politik praktis.

Umat Allah (awam) hendaknya juga tidak menyeret para klerikus ke politik praktis, kecuali Uskupnya melihat keterlibatan tersebut mendesak demi kepentingan gereja dan kesejahteraan umum. Kalau ada klerus yang ngotot untuk terlibat aktif berpolitik praktis tanpa persetujaun pemimpinnya, bukan saja bertentangan dengan KHK, tetapi bertentangan dengan kesadaran pilihan menjadi klerus. Awam yang harus terlibat aktif berpolitik praktis dan bekerja sama dengan para klerus untuk memajukan kader serta mencari jalan-jalan serta tindakan-tindakan yang etis untuk kemajuan umat Katolik dan masyarakat secara umum. Kehidupan masyarakat (demokrasi) dalam satu negara "tidak dapat produktif tanpa keterlibatan setiap orang secara aktif, bertanggungjawab dan murah hati, 'meskupun dalam bentuk, tingkat, tugas dan tangggung jawab yang berbeda-beda dan saling melengkapi.",26

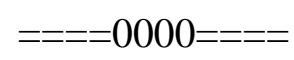

${ }^{26}$ Ratzinger, Joseph. Catatan Ajaran pada Beberapa Pertanyaan..., no. 1. 


\section{DAFTAR PUSTAKA}

Bertens, K. Sejarah Filsafat Yunani, Yogyakarta: Kanisisu, 1987.

Compagnoni, Francesco et al. Nuovo Dizionario di Teologia Morale, Torino: San Paolo, 1990.

Dokumen Konsili Vatikan II, diterjemahkan oleh R. Hardawiryana, Jakarta: Komunetasi dan Penerangan KWI - Obor, 1993.

Kitab Hukum Kanonik (Codex Iuris Canonici, 1983). Diterjemahkan oleh Sekretariat KWI. Jakarta: Obor, 1999.

Magnis-Suseno, Franz. Katolik itu Apa, Sosok, Ajaran, Kesaksiannya, Yogyakarta: Kanisisus, 2017.

Mali, Mateus. Konsep Berpolitik Orang Kristiani. Yogyakarta: Kanisius, 2014.

Ratzinger, Joseph. Catatan Ajaran pada Beberapa Pertanyaan Berhubung dengan Peranserta Umat Katolik di dalam Kehidupan Politik, Jakarta: Dokpen KWI, 2003.

Susetyo, Benny, Hancurnya Etika Politik, Jakarta: Penerbit Buku Kompas, 2004.

Sekretariat KWI, Kitab Hukum Kanonik (Codex Iuris Canonici), Jakarta: Obor, 1999.

Sinaga, Anicetus B. et al. Etos dan Moralitas Politik, Seni Pengabdian untuk Kesejahteraan Umum, Yogyakarta: Kanisius, 2004.

Vidal, Marciano, Manuale di Etica Teologica 3, Morale Sociale, Assisi: Cittadella, 1997. 